\title{
The planning, development, and implementation of a work-site health promotion program: A case study
}

\author{
JOHN C. LICCIARDONE, DO
}

A voluntary health promotion program was introduced at an academic institution with 665 employees. The 239 employees who volunteered to participate in a health risk appraisal were significantly younger and more likely to be female than were nonparticipants. The prevalence rates of the major coronary heart disease risk factors in the participants were as follows: hypercholesterolemia, $25.5 \%$; elevated blood pressure, $15.5 \%$; and current cigarette smoker, $15.1 \%$. In addition, many participants daily consumed food high in cholesterol or fat $(54.2 \%)$, were obese $(44.8 \%)$, and led sedentary lifestyles (28.5\%). Although a majority of female participants had received physician/nurse breast examinations and had Papanicolaou smears taken during the previous year, only about half this number performed monthly breast self-examinations. A telephone survey of employees revealed the most desired health promotion program components to be stress reduction, nutrition counseling, exercise fitness, and weight reduction. The program is now being monitored for health benefits and program costs.

\footnotetext{
Dr Licciardone is research director, Department of Public Health and Preventive Medicine, Texas College of Osteopathic Medicine, Fort Worth.

Reprint requests to John C. Licciardone, DO, Department of Public Health and Preventive Medicine, Texas College of Osteopathic Medicine, 3500 Camp Bowie Blvd, Fort Worth, TX 76107.
}

(Key words: Health promotion, disease prevention, health risk appraisal, survey methods)

During the $1980 \mathrm{~s}$, a trend began toward work-site health promotion or "wellness" programs in the United States. Several explanations have been advanced for this growth of employee-oriented health programs. One theory frequently cited is that health promotion programs can reduce the healthcare costs of the employer. Walsh ${ }^{1}$ points out that a better statement of this theory is that such programs may contain, stabilize, or manage healthcare costs. In any case, potential benefits include reductions in disability and death benefits, absenteeism, on-the-job accidents, turnover rates, and replacement costs as well as increased productivity and improved employee morale, health, and quality of life. ${ }^{2}$

The move toward health promotion has been so strong that many major corporations have adopted these programs based on their intuitive appeal rather than on scientific needs assessment, evaluation, or cost analysis. ${ }^{3}$ However, such studies can be complex. As suggested by Russell, ${ }^{4}$ factors to be considered include the sociodemographic characteristics of the employee population, the frequency of participation and health screening, the magnitude of the disease risks to be averted, the value that the employer and employee place on health promotion, and the time lag between participation in health promotion activities and demonstrable benefits. Kaman ${ }^{5}$ has re- 
viewed the literature regarding costs and benefits of corporate health promotion programs and reported that many have established a favorable benefit-to-cost ratio.

The case study presented here describes the introduction of a health promotion program at an academic institution. Because the program has been in existence for only a short time, the focus here is on the initial planning, development, and implementation rather than an evaluation of changes in the health of the work force or a determination of the program's costs and benefits.

\section{Methods}

A health promotion program was introduced at the Texas College of Osteopathic Medicine (TCOM), Fort Worth, Tex, in 1988. The Texas College of Osteopathic Medicine employed a full-time work force of 665 persons during this period. The program was introduced primarily in order to improve employee health and quality of life. Increased productivity, decreased absenteeism, and decreased employer healthcare expenditures were secondary factors. A wellness committee-which included a chairman, medical director, program director, and several employee members - was appointed to plan, develop, and implement the program.

Most employees were engaged in white collar and other office-based occupations. These were state employees with no union representation. Most were not directly involved in providing healthcare. No previous surveys providing detailed baseline data on the health status of the employees were available. However, a recent TCOM policy statement had banned cigarette smoking at the work site.

An initial goal of the wellness committee was to increase awareness of the program among TCOM employees. This effort was undertaken in May 1988 with a contest in which employees contributed suggestions for the name of the program. A total of 49 names were submitted and a logo was developed to promote the winning program nameHealthSaver. Next, a series of weekly presentations were made during June and July on topics related to health promotion. Topics included cholesterol, heart disease, hypertension, stress, obesity, smoking, cancer, exercise, alcohol consumption, and seat belt use. The final presentation focused on risk evaluation and health risk appraisal.

Next came recruitment of participants for the health risk appraisal phase. Although participa- tion was voluntary, the committee made a strong effort to recruit as many employees as possible. A committee member visited each department, answered questions about the health risk appraisal and the promotion program in general, and scheduled employees for a specific time and date for participation in the health risk appraisal. Employees who did not keep their health risk appraisal appointment were followed up by telephone.

The health risk appraisal was conducted daily between $8 \mathrm{AM}$ and $5 \mathrm{PM}$ during the week of August 8 through 12. Special sessions were scheduled for evening shift employees and those on vacation during the initial assessment period. The health risk appraisal used the "HEALTHIER PEOPLE" program distributed by the Carter Center of Emory University. ${ }^{6}$ This is a probability-based adult health risk appraisal program for the public domain. Participants completed a brief questionnaire that included space for measurements of height, weight, body frame, blood pressure, and cholesterol level.

Blood pressure measurements were made by technicians and repeated if they were found to be elevated (systolic blood pressure $\geq 140 \mathrm{~mm} \mathrm{Hg}$ or diastolic blood pressure $\geq 90 \mathrm{~mm} \mathrm{Hg}$ ). When multiple measurements were made, the lowest blood pressure reading was recorded. Cholesterol measures were made with the Abbott Vision analyzer, using capillary blood from a fingerstick. This method was used to minimize costs. Proper use of the instrument produces measurements that meet accuracy and precision goals established by the National Cholesterol Education Program. ${ }^{7}$ High-density-lipoprotein cholesterol was not measured.

All questionnaires were coded to ensure participant confidentiality. Only the wellness committee chairman had access to these codes in order to disseminate participant reports and medical recommendations. The total time spent by an employee in the health risk appraisal process was approximately 0.5 hour.

Data from the health risk appraisals were processed and a standard "HEALTHIER PEOPLE" report was generated for each participant. This report included information on each participant's current health risks, achievable improvements in health risk, the 12 leading causes of death, percent of ideal body weight, recommendations for reducing risk years, and advice for disease prevention and health promotion. The health risk appraisal reports were distributed to the participants during group sessions in September, and a facilitator assisted the participants in interpreting the 
results. A group report was generated as well.

The medical director reviewed each participant's blood pressure, cholesterol, and percent of ideal body weight. In reviewing these data, the classification systems of the National High Blood Pressure Education Program ${ }^{8}$ and the National Cholesterol Education Program ${ }^{9}$ were used. Participants were notified and advised to consider further evaluation if any of the following conditions were noted: systolic blood pressure $\geq 140 \mathrm{~mm} \mathrm{Hg}$, diastolic blood pressure $\geq 90 \mathrm{~mm} \mathrm{Hg}$, cholesterol $\geq 200 \mathrm{mg} / \mathrm{dL}$, or body weight $\geq 120 \%$ of ideal body weight.

To supplement the health risk appraisal, a telephone survey using the total design method ${ }^{10}$ was conducted in July to establish employee preferences for components of a health education program. A random sample of $10 \%$ of the work force was surveyed. Questionnaire items requested information on program components, day and time preferences, and willingness to pay for program offerings.

\section{Results}

A total of 239 employees (35.9\%) participated in the health risk appraisal. A sociodemographic comparison of the participants and nonparticipants is presented in Table 1 . Significant differences were noted between the two groups, with greater participation among the younger employees and women. There was also a trend toward greater participation by white than by nonwhite employees. Sixty-five participants $(27.7 \%)$ rated their health as excellent; $136(57.9 \%)$, good; 33 (14.0\%), fair; and $1(0.4 \%)$, poor. A total of 168 participants $(70.9 \%)$ considered themselves mainly satisfied with their lives; $60(25.3 \%)$, partly satisfied; and $9(3.8 \%)$, not satisfied.

The prevalence rates of the major coronary heart disease risk factors were as follows: hypercholesterolemia, $25.5 \%$; elevated blood pressure, $15.5 \%$; and current cigarette smoker, $15.1 \%$. Lifestyle and health behavioral factors are presented in Table 2. A majority of the participants wore seat belts regularly $(87.4 \%)$ and consumed food high in fiber on a daily basis (87.8\%). However, many participants daily consumed food high in cholesterol $(54.2 \%)$, were obese $(44.8 \%)$, and led sedentary lives $(28.5 \%$ participated in physical activity sessions less than once a week).
Cancer prevention behaviors among the 159 female participants are presented in Table 3. A majority of the women had had physician/ nurse breast examination (56.0\%) and Papanicolaou smears $(52.8 \%)$ within the previous year. However, only $28.5 \%$ of the women performed monthly breast self-examination.

The telephone survey included 65 employees ( 24 men and 41 women), of whom 59 $(90.8 \%)$ responded. Stress reduction was the most frequently desired component of the program $(27.1 \%)$, followed by nutrition counseling $(20.3 \%)$, exercise fitness $(15.3 \%)$, weight reduction $(10.2 \%)$, smoking cessation $(8.5 \%)$, healthy heart $(5.1 \%)$, and healthy back $(5.1 \%)$. There was relatively little interest in cancer education $(1.7 \%)$ and none in alcohol and drug education. A small percentage of respondents (8.1\%) were willing to pay more than $\$ 20$ for a desired component of the program, but a majority $(62.2 \%)$ were not willing to pay more than $\$ 5$.

\section{Discussion}

Academic institutions, such as the one described here, are adversely affected by the escalating costs of employee healthcare, but they usually do not have the personnel nor the capital necessary for maintaining an independent health promotion program or facility. Cooperation among administrators, supervisors, and employees was necessary in the case of our institution in order to overcome these problems.

At our facility, the director of the wellness committee as well as several committee members were long-term, respected employees. This was an important factor in overcoming barriers to employee participation. The human resource services department was also actively involved in the plan because many of the proposed program activities will either directly or indirectly affect employee benefits, morale, absenteeism, work performance, and healthcare claims. The program director had expertise in exercise programs, nutrition, and marketing, and the medical director was a board-certified preventive medicine specialist.

It is important to note that, with the exception of the medical director, no employees on the wellness committee were involved in pa- 
Table 1

Sociodemographic Characteristics of Employees According to Participation in Health Risk Appraisal

\begin{tabular}{|c|c|c|c|c|c|c|c|c|c|}
\hline \multirow[b]{3}{*}{ Variable } & \multirow{3}{*}{$\frac{\text { Age, } y r}{\text { Mean } \pm \text { SD }^{*}}$} & \multicolumn{4}{|c|}{ Gender } & \multicolumn{4}{|c|}{ Race } \\
\hline & & \multicolumn{2}{|c|}{ Male } & \multicolumn{2}{|c|}{ Female } & \multicolumn{2}{|c|}{ White } & \multicolumn{2}{|c|}{ Nonwhite } \\
\hline & & No. & $\%$ & No. & $\%$ & No. & $\%$ & No. & $\%$ \\
\hline $\begin{array}{l}\text { - Participants } \\
(\mathrm{n}=239)\end{array}$ & $39.0 \pm 11.2$ & 80 & 33.5 & 159 & 66.5 & 221 & 92.5 & 18 & 7.5 \\
\hline $\begin{array}{l}\text { Nonparticipants } \\
(\mathrm{n}=426)\end{array}$ & $41.7 \pm 11.4$ & 192 & 45.1 & 234 & 54.9 & 377 & 88.5 & 49 & 11.5 \\
\hline$P$ value ${ }^{\dagger}$ & .003 & & & & & & & & \\
\hline
\end{tabular}

tient care. It appears feasible for other types of academic institutions to also initiate health promotion programs with minimal external consultation. In choosing a medical consultant, it is important to select a person with expertise in dealing with the health of groups and in applying the principles of health screening. Clearly, the focus of the activities should be on prevention rather than treatment.

Of the 239 employees in the TCOM health risk appraisal, more than $85 \%$ rated their health as either excellent or good. This fact suggests that voluntary participation in a health promotion program may result in the self-selection of relatively healthy persons. The younger age and higher frequencies of female and white employees among participants might also be viewed as support for this belief. Nevertheless, Lynch and colleagues, ${ }^{11}$ in their study of self-selected responders to a health risk appraisal, found that although responders were younger than nonresponders, they were more likely to file healthcare claims. It should also be noted that in the case of the TCOM appraisal the effect of the medical college environment on participation is unknown.

The health promotion program was subsequently offered to all 665 TCOM employees. The initial program offerings included stress reduction workshops, nutrition counseling, weight reduction programs, exercise fitness classes, and smoking cessation programs. This initial phase of the program was accomplished in 1 year and within the annual operating budget of $\$ 5000$ - considerably less than the amount budgeted at many other sites. ${ }^{12}$ Most activities were provided at no cost to the employees.

Plans are currently being developed to expand the activities and to determine cost-effectiveness by estimating the total costs required to achieve certain health goals, such as the saving of a year of life. Moreover, the feasibility of charging fees for certain activities must be further evaluated because most of the survey respondents were unwilling to pay more than the nominal fee of $\$ 5$ for a desired program.

A majority of the female participants had received a breast examination and had a $\mathrm{Pa}$ panicolaou smear taken within the previous year. This was the first health risk appraisal and, therefore, age-specific analyses were not conducted because of limited sample size. Regardless of age, the low prevalence of women performing monthly breast self-examinations is disturbing, particularly in view of the low priority assigned to cancer education in the telephone survey. Alcohol and drug education was also a low-priority area. These findings suggest that more needs to be done to address health promotion in areas not directly related to coronary heart disease.

The findings also suggest the emergence of 
employee stress as a leading form of "occupational disease." Although the deleterious effects of work-site stress may be related to preexisting medical or physical conditions, more than 26 states currently recognize mental stress claims as legitimate. ${ }^{13}$ To combat this trend toward stress as an occupational disease, TCOM and many other employers are now expanding employee assistance programs to include services that address stress management, either directly or indirectly.

Finally, it is useful to compare the TCOM experience in introducing a health promotion program with the activities reported at other work sites. Fielding and Piserchia ${ }^{12}$ conducted a national survey of 1358 work sites (a random sample of all private sector work sites with 50 or more employees). They found the following activities in the percentages indicated being offered in 1984 at work sites having 250 to 749 employees: stress management (37.6\%), exercise fitness $(32.4 \%)$, weight control $(22.5 \%)$, and nutrition education $(21.9 \%)$.

Table 2

Lifestyle and Health Behavioral Factors Among Health Risk Appraisal Participants $(n=239)$

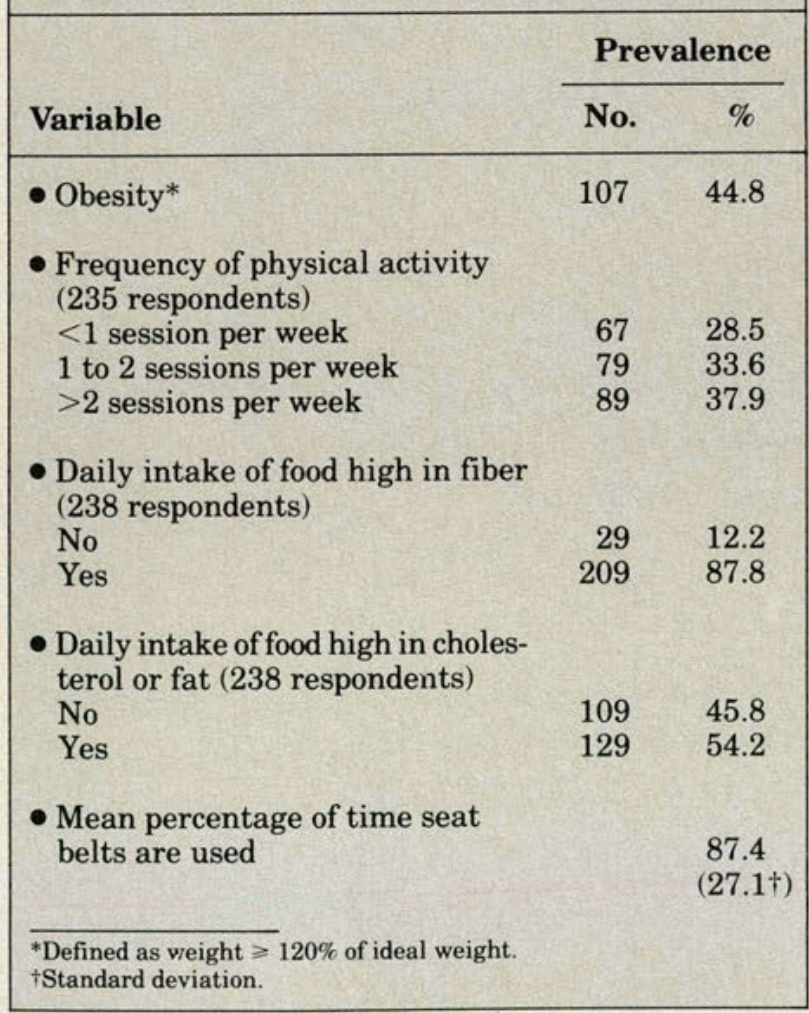

However, unlike the program at TCOM, activities at these locations included a high prevalence of back problems and preventive care $(40.7 \%)$, smoking cessation (40.0\%), and off-thejob accident prevention (33.1\%). Although it may reflect the more sedentary and less hazardous activities of TCOM employees, the low level of interest in a healthy back component of the program at this osteopathic medical institution is puzzling. The low prevalence of cigarette smokers may explain the relative lack of demand for a smoking cessation program.

\section{Comment}

Health risk appraisal and a telephone survey were used to identify desired health promotion activities at an academic institution with 665 employees. To date, the planning, development, and implementation of the program have been accomplished at a modest cost. However, health benefits and cost-effectiveness remain to be determined as more data are collected on health effects and program costs.

\begin{tabular}{|c|c|c|}
\hline \multicolumn{3}{|c|}{$\begin{array}{c}\text { Table } 3 \\
\text { Cancer Preventive Behaviors Among } \\
\text { Female Health Risk Appraisal Participants } \\
(\mathbf{n}=159)\end{array}$} \\
\hline \multirow[b]{2}{*}{ Behavior } & \multicolumn{2}{|c|}{ Responses } \\
\hline & No. & $\%$ \\
\hline \multicolumn{3}{|c|}{$\begin{array}{l}\text { Interval since breast exam- } \\
\text { ination by physician/nurse } \\
\text { (159 respondents) }\end{array}$} \\
\hline$<1$ year & 89 & 56.0 \\
\hline 1 year & 29 & 18.2 \\
\hline 2 years & 24 & 15.1 \\
\hline$>2$ years & 14 & 8.8 \\
\hline Never examined & 3 & 1.9 \\
\hline \multicolumn{3}{|c|}{$\begin{array}{l}\text { - Frequency of breast self-exami- } \\
\text { nation (158 respondents) }\end{array}$} \\
\hline Monthly & 45 & 28.5 \\
\hline Once every few months & 63 & 39.9 \\
\hline Never or rarely & 50 & 31.6 \\
\hline \multicolumn{3}{|c|}{$\begin{array}{l}\text { - Interval since last Papanicolaou } \\
\text { smear (159 respondents) }\end{array}$} \\
\hline$<1$ year & 84 & 52.8 \\
\hline 1 year & 28 & 17.6 \\
\hline 2 years & 27 & 17.0 \\
\hline$>2$ years & 15 & 9.4 \\
\hline Never examined & 5 & 3.2 \\
\hline
\end{tabular}




\section{References}

1. Walsh DC: Toward a sociology of work-site health promotion: A few reactions and reflections. Soc Sci Med 1988;26:569575 .

2. Hollander RB, Lengermann JJ, DeMuth NM: Cost-effectiveness and cost-benefit analyses of occupational health promotion, in Everly GS, et al (eds): Occupational Health Promotion: Health Behavior in the Workplace. New York, NY John Wiley \& Sons, 1986.

3. Walsh DC, Egdahl RH: Corporate perspectives on work-site wellness programs: A report on the Seventh Pew Fellows Conference. J Occup Med 1989;31:551-556.

4. Russell LB: Is Prevention Better Than Cure? Washington, DC, The Brookings Institution, 1986.

5. Kaman RL: Costs and benefits of corporate health promotion. Fitness in Business 1987;2(October):39-44.

6. Amler RW, Moriarty DG, Hutchins EB (eds): HEALTHIER PEOPLE: The Carter Center of Emory University Health Risk Appraisal Program. Guides and Documentation. Decatur, Ga, The Carter Center of Emory University, 1989.
7. Burke JJ II, Fischer PM: A clinician's guide to the office measurement of cholesterol. JAMA 1988;259:3444-3448.

8. National High Blood Pressure Education Program: The 1988 Report of the Joint National Committee on Detection, Evaluation, and Treatment of High Blood Pressure. Washington, DC, National Institutes of Health, 1988.

9. National Cholesterol Education Program: Report of the Expert Panel on Detection, Evaluation, and Treatment of High Blood Cholesterol in Adults. Washington, DC, National Institutes of Health, 1988.

10. Dillman DA: Mail and Telephone Surveys: The Total Design Method. New York, NY, John Wiley \& Sons, 1978.

11. Lynch WD, Golaszewski TJ, Clearie A, et al: Characteristics of self-selected responders to a health risk appraisal: Generalizability of corporate health assessments. Am J Public Health 1989;79:887-888.

12. Fielding JE, Piserchia PV: Frequency of worksite health promotion activities. Am J Public Health 1989;79:16-20.

13. Donatelle RJ, Hawkins MJ: Employee stress claims: Increasing implications for health promotion programming. American Journal of Health Promotion 1989;3(Winter):19-25. 